\title{
The Construction of Nonlinear Dynamic System Model of National Defense Expenditure and Economic Growth
}

\author{
Xiuyuan Peng ${ }^{1, a}$ and Jianjun Han ${ }^{1, b}$ \\ ${ }^{1}$ Logistics University of People's Armed Police Force, Tianjin, P.R. China \\ a516763055@qq.com, b446806854@qq.com
}

Keywords: Nonlinear dynamic system; Defense expenditure; Economic growth; GDP; Defense.

\begin{abstract}
At present, the domestic and foreign scholars mainly use the co integration test to study the relationship between defense spending and economic growth. These methods mainly study the relationship from the point of view of the data, which can only come to the long-term stable relationship or causal relationship between the two, not specifically found how the relationship between defense spending and economic growth is. In this paper, a dynamic economic approach is used to establish the DE-GDPNLDS nonlinear dynamic system model between defense expenditure and economic growth.
\end{abstract}

\section{The Complex Role of Defense Spending and Economic Growth}

We first look at the trends in 1979 -2013 years (Fig. 1).

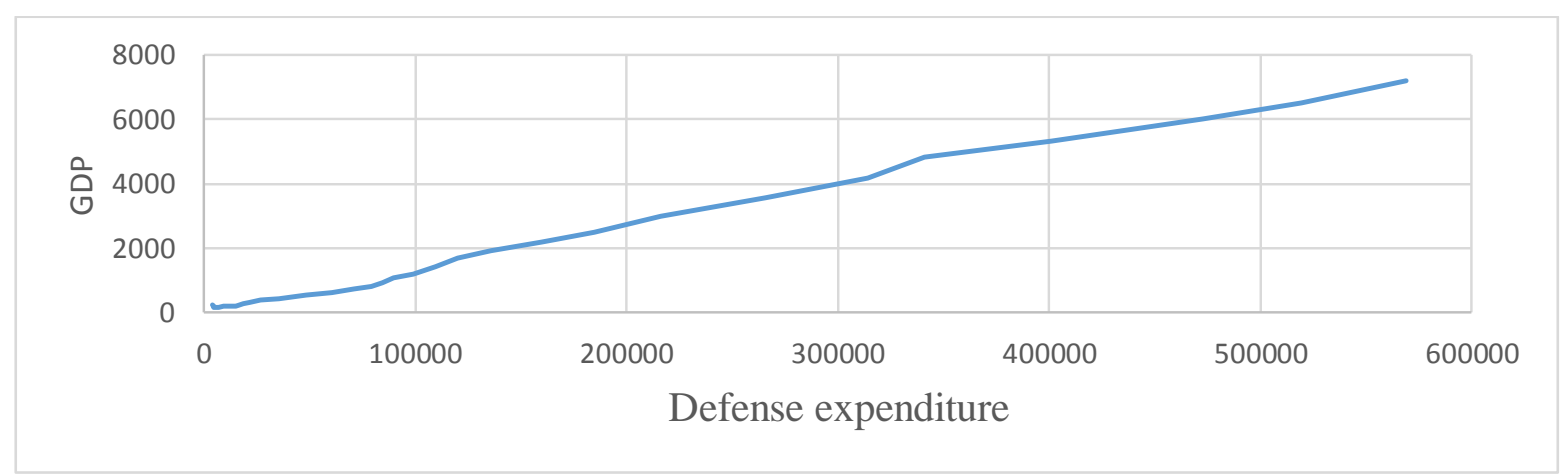

Figure 1. 1979-2013 China's defense spending and GDP scatter plot

From Fig. 1 we can see that: The scatter diagram between defense spending and GDP is not a straight line, so there should be a nonlinear relationship between them. In addition, we can also look at the relationship between them from a long time trend chart, see Fig. 2, 3.

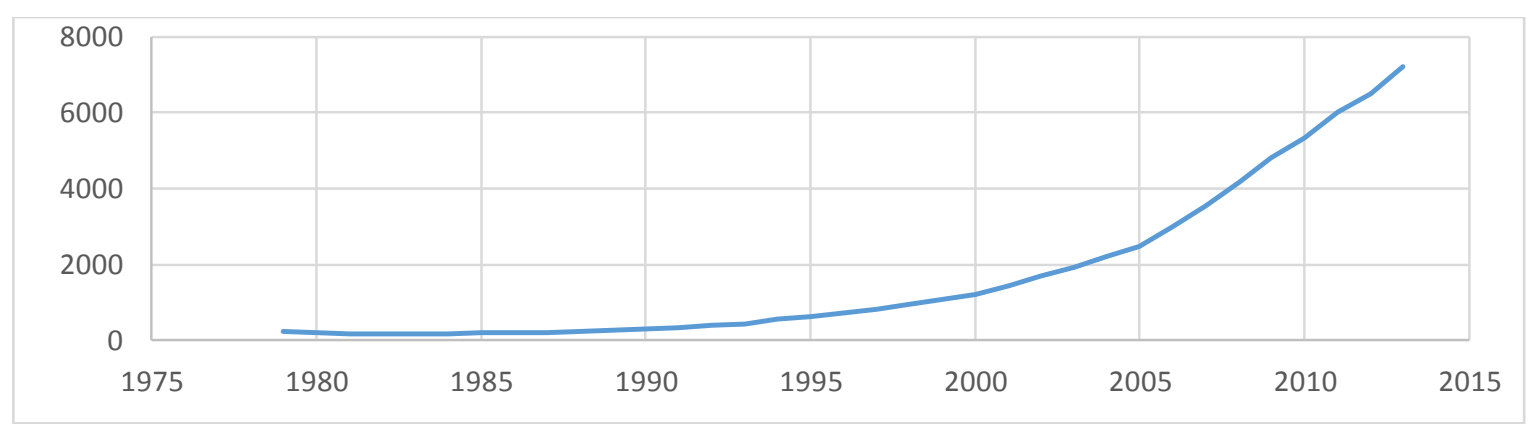

Figure 2. 1979-2013 years of China's defense spending scale trend chart 


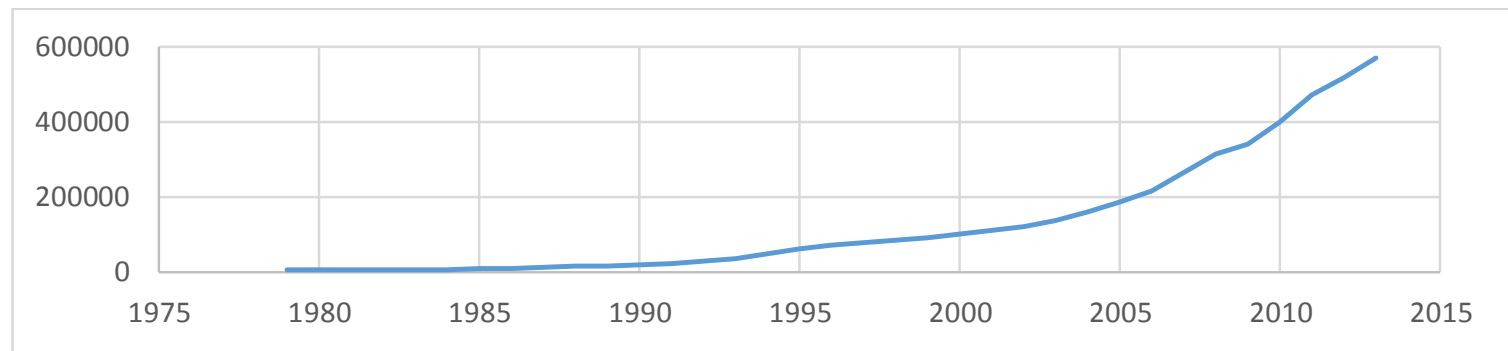

Figure 3. 1979-2013 China GDP trend chart

From Fig. 2, Fig. 3 can obviously see 1979- 1995, China's GDP growth rate is far greater than the increase in defense spending.

To find out how this kind of nonlinear relationship, we need to establish a nonlinear model between them. According to the theory of system science, there is a complex interaction between defense expenditure and economic growth, and a complex system has been formed between them. This kind of relation exists mainly in the form of nonlinear: Authigenic effect, Coupling effect, Spillover effect.

\section{Nonlinear Dynamic System Model of the Defense Expenditure and the Economic Growth}

We selected from 1979 to 2013 between data samples, the analysis of defense spending (DE) and economic growth (GDP) between the nonlinear relationship. DE-GDPNLDS a differential dynamic model is established.

Hypothesis of the Model. 1. the assumption that DE-GDPNLDS formed by the nonlinear interaction de between GDP and complex system with certain structure and function, the system in time is continuous, and independent of any spatial distribution, and is not affected by the influence of other variables.

2. In the empirical study, we regard the DE-GDPNLDS system as a discrete, differential system. No matter whether the process of DE and GDP is stable or not, we can use statistical data to establish the difference equation.

3. As long as the impact of random factors DE-GDPNLDS system is stable, we cannot consider the impact of these factors on the system, only consider the DE and GDP between the deterministic relationship.

Model Building. The DE-GDPNLDS differential dynamic model is established:

$$
\left\{\begin{array}{l}
\frac{d D E}{d t}=\alpha_{0}+\alpha_{1} D E+\alpha_{2} D E^{2}+\alpha_{3} D E * G D P+\alpha_{4} G D P+\alpha_{5} G D P^{2}+\alpha_{6} t \\
\frac{d G D P}{d t}=\beta_{0}+\beta_{1} G D P+\beta_{2} G D P^{2}+\beta_{3} D E * G D P+\beta_{4} D E+\beta_{5} D E^{2}+\beta_{6} t
\end{array}\right.
$$

Model (1) including the de between GDP and authigenic effect $\left(\alpha_{0}+\alpha_{1} D E+\alpha_{2} D E^{2}, \beta_{0}+\right.$ $\left.\beta_{1} G D P+\beta_{2} G D P^{2}\right)$, coupling effect $\left(\alpha_{3} D E * G D P, \beta_{3} D E * G D P\right)$, overflow effect $\left(\alpha_{4} G D P+\alpha_{5} G D P^{2}, \beta_{4} D E+\beta_{5} D E^{2}\right)$.

Based on the assumption of the model, we use the econometric Model (1) to measure the economic learning Model (2):

$$
\left\{\begin{array}{l}
D E_{t+1}=\alpha_{0}+\left(\alpha_{1}+1\right) D E_{1}+\alpha_{2} D E_{1}^{2}+\alpha_{3} D E_{1} * G D P_{1}+\alpha_{4} G D P_{1}+\alpha_{5} G D P_{1}^{2}+\mu_{1} \\
G D P_{t+1}=\beta_{0}+\left(\beta_{1}+1\right) G D P_{1}+\beta_{2} G D P_{1}^{2}+\beta_{3} D E_{1} * G D P_{1}+\beta_{4} D E_{1}+\beta_{5} D E_{1}{ }^{2}+\mu_{2}
\end{array}\right.
$$




\section{Data Sources, Processing and Description}

Sample interval selected 1978-2013, this stage of the data is more reference. Measurement data from China's National Bureau of statistics official website.

Variable Stability and Single Integer Test. The most commonly used test method is the ADF test, the test selection 5\% confidence level, the results see Table 1.

Table 1 DE, GDP variable ADF test results

\begin{tabular}{llll}
\hline sequence & Critical value of ADF test & T statistic & The value of $P$ \\
\hline DE & -3.544284 & 1.002148 & 0.9998 \\
GDP & -3.548490 & 0.881215 & 0.9997 \\
\hline
\end{tabular}

Under the significant level of 5\%, the DE sequence and the GDP sequence accepted the original hypothesis at the significant level of more than $99.9 \%$, that is the conclusion of the unit root. In this way, it can be judged that the DE sequence and GDP sequence are non-stationary time series.

Determine the Model 2 in the various variables of the single integer order.

Table 2 DE, GDP variable ADF test results

\begin{tabular}{ccc}
\hline variable & Critical value of ADF test & T statistic \\
\hline $\mathrm{DE}_{\mathrm{t}+1}$ & -3.548490 & 0.200546 \\
$\mathrm{GDP}_{\mathrm{t}+1}$ & -3.552973 & 0.810190 \\
$\mathrm{DE}_{\mathrm{t}}$ & -3.548490 & 0.719812 \\
$\mathrm{DE}_{\mathrm{t}}^{2}$ & -3.548490 & 3.364601 \\
$\mathrm{GDP}$ & -3.574244 & 2.838422 \\
$\mathrm{GDP}_{\mathrm{t}}{ }^{2}$ & -3.595026 & 5.243993 \\
$\mathrm{DE}_{\mathrm{t}} \mathrm{GDP}_{\mathrm{t}}$ & -3.548490 & 8.700185 \\
\hline
\end{tabular}

T statistic in Model 2 variables values were greater than at 5\% significant level of ADF test critical values, which we judge: these variables are non-stationary.

Table 3 the ADF test of each variable in the Model 2 after first order difference

\begin{tabular}{ccc}
\hline variable & Critical value of ADF test & T statistic \\
\hline$\triangle D E_{t+1}$ & -1.951687 & -0.307192 \\
$\triangle G D P_{t+1}$ & -3.552973 & -1.975214 \\
$\triangle D E_{t}$ & -1.952066 & -0.124335 \\
$\triangle D E_{t}^{2}$ & -3.587527 & 0.711300 \\
$\triangle G D P$ & -3.552973 & -1.954380 \\
$\triangle G^{2} P_{t}^{2}$ & -3.562882 & 2.094075 \\
$\triangle D E_{t}{ }^{2} P_{t}$ & -3.587527 & 2.244754 \\
\hline
\end{tabular}

Values of t statistic Model 2 variables in first order differential points were greater than at 5\% significant level of ADF test critical values, which we judge: these variables first-order difference is not smooth.

Table 4 ADF test of two order difference of each variable in the Model 2

\begin{tabular}{ccc}
\hline variable & Critical value of ADF test & T statistic \\
\hline$\triangle^{2} \mathrm{DE}_{\mathrm{t}+1}$ & -2.976263 & -5.589962 \\
$\triangle^{2} \mathrm{GDP}_{\mathrm{t}+1}$ & -1.951687 & -4.986304 \\
$\triangle^{2} \mathrm{DE}_{\mathrm{t}}$ & -1.952066 & -7.944367 \\
$\triangle^{2} \mathrm{DE}_{\mathrm{t}}{ }^{2}$ & -3.587527 & -5.040642 \\
$\triangle^{2} \mathrm{GDP}$ & -1.951687 & -4.742779 \\
$\triangle^{2} \mathrm{GDP}_{\mathrm{t}}{ }^{2}$ & -3.562882 & -6.159784 \\
$\triangle^{2} \mathrm{DE}_{\mathrm{t}}^{*} \mathrm{GDP}_{\mathrm{t}}$ & -2.976263 & -3.474238 \\
\hline
\end{tabular}


Values of t statistic Model 2 variables in second order difference points are less than at 5\% significant level of ADF test critical values, which we judge: these variables of second order difference is smooth.

Parameter Estimation and co Integration Test. Use Eviews8.0 software on the Model 2 with the NLS parameter estimation.

Table 5 The first equation of the Model 2

\begin{tabular}{|c|c|c|c|c|}
\hline variable & $\begin{array}{l}\text { parameter } \\
\text { estimation }\end{array}$ & & T statistic & The value of $P$ \\
\hline constant & -47.40997 & \multirow{8}{*}{3082.901} & -4.060397 & 0.0003 \\
\hline $\mathrm{DE}_{\mathrm{t}}$ & 1.344146 & & 2.192865 & 0.0000 \\
\hline $\mathrm{DE}_{\mathrm{t}} * \mathrm{GDP}_{\mathrm{t}}$ & $-1.41 \mathrm{E}-05$ & & -3.997837 & 0.0004 \\
\hline $\mathrm{GDP}_{\mathrm{t}}^{2}$ & $1.46 \mathrm{E}-07$ & & 3.629283 & 0.0010 \\
\hline $\mathrm{F}$ & & & & 0.000000 \\
\hline $\operatorname{Adj} * R^{2}$ & & & 0.996336 & \\
\hline DW & & & 1.965031 & \\
\hline AIC & & & 8.940802 & \\
\hline
\end{tabular}

Table 6 The second equation of the Model 2

\begin{tabular}{|c|c|c|c|c|}
\hline variable & $\begin{array}{l}\text { parameter } \\
\text { estimation }\end{array}$ & & $\mathrm{T}$ statistic & $\begin{array}{c}\text { The value } \\
\text { of } \mathrm{P}\end{array}$ \\
\hline constant & -996.7392 & & -3.244150 & 0.0028 \\
\hline $\mathrm{GDP}_{\mathrm{t}}$ & 1.053769 & & -45.57676 & 0.0000 \\
\hline $\mathrm{DE}_{\mathrm{t}}$ & 9.073513 & & 3.700355 & 0.0008 \\
\hline $\mathrm{DE}_{\mathrm{t}}^{2}$ & -0.005449 & & -4.053893 & 0.0003 \\
\hline $\mathrm{F}$ & & 26422.78 & & 0.000000 \\
\hline $\operatorname{Adj} * R^{2}$ & & & 0.999571 & \\
\hline DW & & & 1.059621 & \\
\hline AIC & & & 15.57455 & \\
\hline
\end{tabular}

From Table 5 can be seen the first equation $\mathrm{f}$ value is $3082.901, \mathrm{P}=0$. Adj $\bullet \mathrm{R} 2=0.996336$, illustrate the equation was fitted to the good, constant, $\mathrm{DE}_{\mathrm{t}} \mathrm{DE}_{\mathrm{t}} * \mathrm{GDP}_{\mathrm{t}} 、 \mathrm{GDP}_{\mathrm{t}}^{2}$ at $1 \%$ significant level are significant; seen from Table 6, Model 2 of the second equation $\mathrm{F}$ value is $26422.78, \mathrm{P}=0$. $\operatorname{Adj} \cdot R^{2}=0.999571$, illustrate the fitting equation is also very good, constant, GDP $、 D_{t} 、 D_{t}{ }_{t}^{2}$ at $1 \%$ level of significance is significant.

\section{Solving the Model}

Seen from the above analysis, the fitting of two equation Model 2 are very good, so transform the dynamic econometric model to DE-GDPNLDS differential dynamic model:

$$
\left\{\begin{array}{c}
\frac{d D E}{d t}=0.344146 D E-1.41 \times 10^{-5} D E * G D P+1.46 \times 10^{-7} G D P^{2}-47.40997 \\
\quad \frac{d G D P}{d t}=0.05144 G D P+9.593934 D E-0.005822 D E^{2}-1053.905
\end{array}\right.
$$

Model 3, there is no time variable, there are three nonlinear terms, that is, the first equation of $\mathrm{DE}_{\mathrm{t}}{ }^{*} \mathrm{GDP}_{\mathrm{t}}, \mathrm{GDP}_{\mathrm{t}}{ }_{\mathrm{t}}^{2}$, second equations $\mathrm{DE}_{\mathrm{t}}{ }^{2}$. There are three mechanisms for the model: self effect, coupling effect and spillover effect.

From the equation of $\frac{\mathrm{dDE}}{\mathrm{dt}}$ seen de authigenic effect has a positive feedback that De to its growth promoting effect; DE*GDP coupling is negative, indicating that the coupling effect between them to de produced negative effect on the economic growth; and $\mathrm{GDP}^{2}$ term coefficient is positive, that the increase of GDP of DE Long generation accelerate the role is a DE Growth Accelerators.

From the equation of $\frac{\mathrm{dGDP}}{\mathrm{dt}}$ seen GDP mentor effect there is a positive feedback that GDP to its growth promoting effect; de coefficient is positive, de growth will boost GDP growth, but $\mathrm{DE}^{2}$ 
coefficient is negative, to GDP has a negative to the effect that the role of De of GDP is not obvious.

The following conclusions can be drawn from the Model 3:

(1) DE and GDP of the coupling of De effect is negative, the GDP had no effect that de and GDP falls between symbiotic partial harm relations.

(2) The effect of DE on GDP, according to the first equation in the Model 3:

$$
\begin{aligned}
& \frac{\partial \mathrm{DE}}{\partial \mathrm{GDP}}=-1.41 \times 10^{-5} \mathrm{DE}+2.92 \times 10^{-7} G D P>0 \\
& \frac{D E}{G D P}<0.02070922
\end{aligned}
$$

This shows that $\mathrm{DE} / \mathrm{GDP}=0.02070922$ is a critical value, more than this value, $\mathrm{DE}$ on economic development will be hindered, lower than the role of promoting.

(3) The effect of GDP on the DE, according to the Model 3 in the second equations

$$
\frac{\partial G D P}{\partial D E}=9.593934-0.011644 D E>0
$$

We know DE<823.937994

Indicates that $\mathrm{DE}=823.937994$ is the critical value, below this value GDP to promote DE growth, higher than this value when GDP hinder DE growth.

\section{Summary}

DE and GDP of the coupling of DE effect is negative, the GDP had no effect shows that the relationship between de and GDP is type AMENSALISM symbiosis.

The effect of De of GDP: DE/GDP=0.02070922 is a critical value, when more than the critical value of De of GDP will be produced inhibition, when below this value when generating role; the effect of GDP on de: DE=823.937994 is a critical value, when the DE<823.937994 GDP will promote the de growth, when the DE>823.937994, GDP will hinder the DE growth.

DE-GDPNLDS system in the equilibrium point $E_{1}=(2324.61198535 .84)$ stable, this defense burden was $1.17 \%$, that the burden of defense in our country in the future not only does not increase, but there was also a drop in the process, the proportion of far below the estimation of some western countries and some research institutions of China's defense expenditure scale, and from another point of view, refuted the western countries to promote the so-called "China Threat Theory".

\section{References}

[1] Murdoch, J.C., and Sandler, Australian Demand for Military Expenditures, J. Australian Economic Papers, 1985, (6): 142 -15

[2] Gong, Liutang Zou, Heng-fu, Military spending and stochastic growth [J], Journal of Economic Dynamics and Cnortl, 2003, 28:153-170

[3] Xu Yangli. Analysis on the influencing factors of China's military expenditure demand, D. Jilin University, 2013

[4] Wang Ningning, Yang Guang, Analysis on the determinants of fiscal resource allocation in the coordinated development of national defense and economic construction, J. Foreign capital in China, 2013, 23:11

[5] Liu Zuchen, Research on the fiscal policy of national defense in China, D. Finance Science Research Institute of the Ministry of Finance, 2013

[6] Chen Bingfu, China's national defense expenditure demand and policy research, D. Tianjin University, 2006 
[7] Yan Zhongyong, Chen Bo, National defense expenditure, industrial structure and optimal defense burden, J. Journal of Central University of Finance and Economics, 2009,08:1-4

[8] Pak Hung Mo, Government Expenditures and Economic Growth, D. FISCAL STUDIES, vol. 28, NO. 4, 2007, 497-522 